\title{
Mesoporous Carbon as Galvanic-Corrosion Activator Accelerates Fe Degradation
}

\author{
Cijun Shuai ${ }^{1,2,3}$, Yulong Li ${ }^{1}$, Fang Deng ${ }^{1}$, Youwen Yang ${ }^{1, *} \mathbb{C}$, Shuping Peng ${ }^{1, *}$, Fangwei Qi ${ }^{1}$ \\ and Lida Shen ${ }^{4}$ (I) \\ 1 Institute of Bioadditive Manufacturing, Jiangxi University of Science and Technology, Nanchang 330013, \\ China; shuai@csu.edu.cn (C.S.); liyulong_jx@yeah.net (Y.L.); dengfang@jxust.edu.cn (F.D.); \\ qfw@jxust.edu.cn (F.Q.) \\ 2 State Key Laboratory of High Performance Complex Manufacturing, Central South University, \\ Changsha 410083, China \\ 3 School of Intelligent Manufacturing and Equipment, Shenzhen Institute of Information Technology, \\ Shenzhen 518172, China \\ 4 College of Mechanical and Electrical Engineering, Nanjing University of Aeronautics and Astronautics, \\ Nanjing 210016, China; ldshen@nuaa.edu.cn \\ * Correspondence: yangyouwen@csu.edu.cn (Y.Y.); shuping@csu.edu.cn (S.P.)
}

Received: 27 February 2020; Accepted: 2 April 2020; Published: 4 April 2020

\begin{abstract}
Iron ( $\mathrm{Fe})$ has attracted intensive attention as a bone implant material because of its inherent biodegradability, favorable biocompatibility and mechanical properties. Nevertheless, it degrades too slowly in a physiological environment, which limits its further clinical application. In this work, mesoporous carbon (MC) was introduced into Fe bone implant manufactured via a laser-additive manufacturing process. Particularly, MC possesses a noble standard corrosion potential and excellent electrical conductivity, thus acting as an effective cathode and activating micro-galvanic corrosion in the Fe matrix. More importantly, its high specific surface area enhanced the area ratio between cathode and anode, which further enhanced the galvanic corrosion effect. As a consequence, the corrosion rate was enhanced from 0.09 to $0.24 \mathrm{~mm} /$ year based on immersion tests. Besides, Fe/MC composite exhibited good cytocompatibility, as well as excellent mechanical properties. The positive results proved that the $\mathrm{Fe} / \mathrm{MC}$ composite shows great potential as a bone implant.
\end{abstract}

Keywords: mesoporous carbon; Fe bone implant; degradation behavior; laser additive manufacturing

\section{Introduction}

Biodegradable metal materials, including iron (Fe), magnesium and zinc, have currently drawn much attention for their potential bone repair application [1-4]. Among them, Fe is recognized as the preferable choice to provide structure support for the defect bone in load-bearing area due to its excellent mechanical properties [5,6]. Meanwhile, Fe is one of the essential nutritional elements, and involves a variety of oxidases and metabolic enzymes [7,8]. Its favorable biocompatibility has also been confirmed by in vitro and in vivo research $[9,10]$. Unfortunately, Fe degrades too slowly in the physiological environment, which significantly restricts its further clinical orthopedic application [11,12].

To improve the corrosion behavior, previous researchers incorporated the noble phase into Fe matrix as a cathode to enhance micro-galvanic corrosion [13-15]. For instance, Čapek et al. [16] added Pd into Fe, which improved the degradation rate from 0.04 to $0.12 \mathrm{~mm} /$ year. Zhao et al. [17] incorporated graphene oxide into $\mathrm{Fe}$ as a galvanic corrosion couple, which enhanced the degradation rate from 0.09 to $0.41 \mathrm{~mm} /$ year. Mesoporous carbon (MC) possesses a nobler electrode potential $(0.207 \mathrm{~V})$ than Fe $(-0.440 \mathrm{~V})[18]$. More significantly, it possesses a high specific surface area, which can increase 
area ratio between the cathode and anode [19]. Previous studies confirmed that an increased area ratio of cathode and anode could enhance the galvanic corrosion effect [20-22]. Moreover, MC has excellent electrical conductivity, which can decrease the electron transfer resistance and increase corrosion current density $[23,24]$. Thus, $\mathrm{MC}$ is expected to act as an effective galvanic corrosion activator in the Fe matrix. Besides, MC was reported to be of favorable biocompatibility, and has been used as drug delivery for biomedical application [25].

Based on the above considerations, herein, $\mathrm{MC}$ was introduced into Fe matrix aiming to obtain Fe-based composite with tailored degradation rate. Fe/MC composite was manufactured using laser additive manufacturing. Compared with other technologies, laser additive manufacturing can produce bone implants with a complex structure and personalized shape [26-29]. The microstructure characteristic, mechanical properties, as well as the corrosion behavior were studied systematically. Meanwhile, the corresponding corrosion mechanism was elaborated. Moreover, the cytocompatibility of $\mathrm{Fe} / \mathrm{MC}$ composite was also evaluated.

\section{Materials and Methods}

\subsection{Material}

Fe powder $(99.9 \%, \sim 35 \mu \mathrm{m})$ was supplied from Shanghai Naiou Nano technology Co., Ltd, as shown in Figure 1a. MC powder ( $99.9 \%$, average pore diameter of $3.9 \mathrm{~nm}$, length of about $20 \mu \mathrm{m})$ was purchased from Aladdin biochemical Technology Co., Ltd. (Shanghai, China), as shown in Figure $1 b$, which showed a well-ordered mesoporous structure. The physicochemical parameters of MC were listed in Table 1.
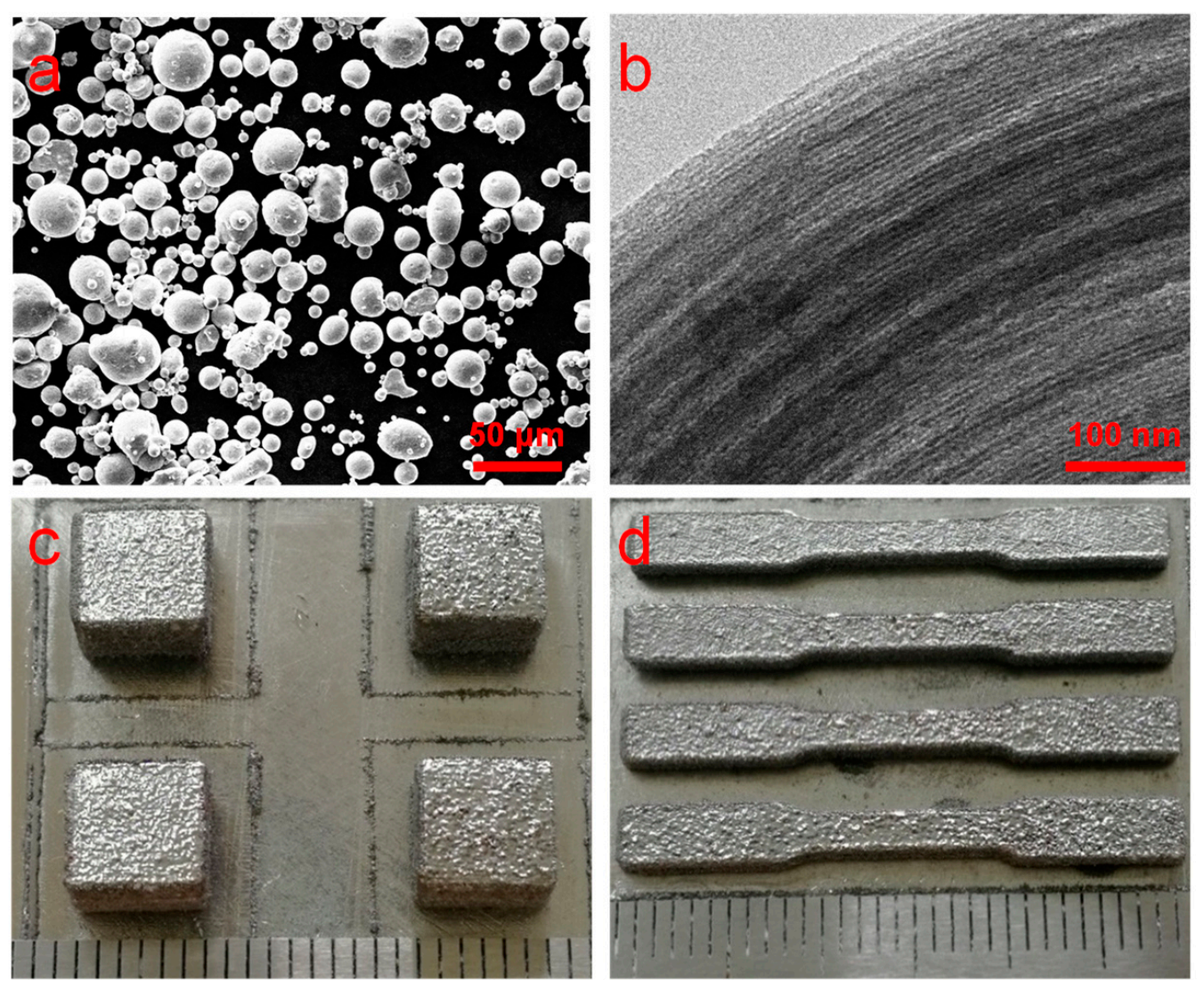

Figure 1. (a) SEM images of as-received Fe powder; (b) Transmission electron micrographs of mesoporous carbon (MC); Photograph showing (c) as-built samples and (d) stretch samples. 
Table 1. Physical and chemical parameters of MC.

\begin{tabular}{cccc}
\hline Micro Porosity $(\%)$ & Pore Diameter $(\mathbf{n m})$ & BET Surface Area $\left(\mathrm{m}^{2} / \mathrm{g}\right)$ & Pore Volume $\left(\mathrm{cm}^{3} / \mathrm{g}\right)$ \\
\hline 3.7 & 3.9 & 1201 & 1.36 \\
\hline
\end{tabular}

\subsection{Fabrication Process}

The MCs with mass fractions of 0, 0.5, 1.0 and $1.5 \mathrm{wt} . \%$, respectively, were mixed with Fe powder in alcoholic solution, and then mechanically stirred at a rotation rate of $300 \mathrm{rpm}$ for $2 \mathrm{~h}$. Subsequently, the $\mathrm{Fe} / \mathrm{MC}$ powders were dried at $60^{\circ} \mathrm{C}$ for $10 \mathrm{~h}$. The $\mathrm{Fe} / \mathrm{MC}$ composites were prepared on a home-made selective laser melting (SLM) machine, which consisted of a powder delivery system, a galvanometer scanner, intelligent purification cycle system and dust removal system. High-purity argon $(99.999 \%)$ was provided during experiments. Based on a series of preliminary experiments, the optimal process parameters were set at laser power $110 \mathrm{~W}$, scanning speed $170 \mathrm{~mm} / \mathrm{s}$, layer thickness $80 \mu \mathrm{m}$, scanning distance $50 \mu \mathrm{m}$. The SLM-fabricated samples with a size of $6 \times 6 \times 6 \mathrm{~mm}^{3}$ were exhibited in Figure 1c. These samples contained MC with a nominal content of 0, 0.5, 1.0 and $1.5 \mathrm{wt} . \%$, and were described as $\mathrm{Fe}, \mathrm{Fe} / 0.5 \mathrm{MC}, \mathrm{Fe} / 1.0 \mathrm{MC}$ and $\mathrm{Fe} / 1.5 \mathrm{MC}$, respectively.

\subsection{Microstructure Characterization}

The as-built parts were mechanically polished using metallographic sandpaper up to 1500 grits and ultrasonically cleaned in anhydrous ethanol. The microstructure was analyzed using a scanning electron microscopy (SEM, ZEISS, Germany) combined with an energy dispersive spectrometer (EDS). The phase composition was studied by using an x-ray diffractometer (XRD, Karlsruhe, Germany) at $8^{\circ} / \mathrm{min}$ from 10 to $90^{\circ}$. The mechanical tests were performed using a universal test machine. The tensile samples were prepared basing on GBT228-2002, as shown in Figure 1d. The tensile tests were conducted at a crosshead rate of $1 \mathrm{~mm} / \mathrm{min}$. In addition, the fracture surfaces obtained by tensile tests were investigated using SEM.

\subsection{Electrochemical Experiments}

The electrochemical tests were performed on a three-electrode electrochemical workstation (CHI660E, $\mathrm{CH}$ Instruments Inc.). In these tests, the specimen was set as the working electrode. A platinum mesh and a saturated $\mathrm{Ag} / \mathrm{AgCl}(\mathrm{Sat} . \mathrm{KCl}$ ) electrode were selected as the counter electrode and reference electrode, respectively. The whole experimental process was performed at $37^{\circ} \mathrm{C}$ in a electrolytic cell using simulated body fluid (SBF) as the electrolyte, which was composed of $\mathrm{NaCl}$ $(8.035 \mathrm{~g} / \mathrm{L}), \mathrm{NaHCO}_{3}(0.355 \mathrm{~g} / \mathrm{L}), \mathrm{KCl}(0.225 \mathrm{~g} / \mathrm{L}), \mathrm{K}_{2} \mathrm{HPO}_{4} \cdot 3 \mathrm{H}_{2} \mathrm{O}(0.231 \mathrm{~g} / \mathrm{L}), \mathrm{MgCl}_{2} \cdot 6 \mathrm{H}_{2} \mathrm{O}(0.311 \mathrm{~g} / \mathrm{L})$, $\mathrm{CaCl}_{2}(0.292 \mathrm{~g} / \mathrm{L}), \mathrm{Na}_{2} \mathrm{SO}_{4}(0.072 \mathrm{~g} / \mathrm{L})$. The open circuit potential (OCP) was monitored for $3600 \mathrm{~s}$. The electrochemical impedance spectroscopy (EIS) was conducted ranging from 0.01 to $100,000 \mathrm{~Hz}$ using a peak-to-peak $10 \mathrm{mV}$ sinusoidal perturbation. Potentiodynamic polarization test was performed at a sweep rate of $0.2 \mathrm{mV} / \mathrm{s}$. The corrosion rates $(\mathrm{CR}, \mathrm{mm} / \mathrm{year})$ basing on electrochemical tests were determined by

$$
\mathrm{CR}=3.27 \times 10^{3} \times \mathrm{i}_{\text {corr }} \times \mathrm{W} / \mathrm{\rho}
$$

where $\mathrm{i}_{\text {corr }}\left(\mu \mathrm{A} / \mathrm{cm}^{2}\right)$ represented the corrosion current density, $\rho\left(\mathrm{g} / \mathrm{cm}^{-3}\right)$ was the density, and $\mathrm{W}$ was the equivalent weight. Herein, the $\mathrm{W}$ was $27.92 \mathrm{~g} / \mathrm{eq}$. Meanwhile, the electrochemical corrosion surface was observed using SEM.

\subsection{Immersion Tests}

Immersion tests were performed in SBF at $37^{\circ} \mathrm{C}$ with an exposed surface area to a solution volume ratio of $0.1 \mathrm{~cm}^{2} / \mathrm{mL}$. After immersion for 7, 14, 21 and $28 \mathrm{~d}$, the corrosion products on specimens were removed based on ASTM G1-03. Subsequently, specimens were ultrasonically cleaned for $15 \mathrm{~min}$, 
washed with distilled water and then dried for $12 \mathrm{~h}$ before weighing. The degradation rate (DR, $\mathrm{mm}$ /year) basing on immersion tests was calculated by the following formula

$$
\mathrm{DR}=8.76 \times 10^{4} \times \mathrm{M} /(\mathrm{A} \times \mathrm{T} \times \mathrm{D})
$$

where $\mathrm{M}(\mathrm{g}), \mathrm{T}(\mathrm{h}), \mathrm{A}\left(\mathrm{cm}^{2}\right)$ and $\mathrm{D}\left(\mathrm{g} \cdot \mathrm{cm}^{-3}\right)$ were the weight loss, immersion time, exposed surface area, and the density, respectively. The Fe ion concentration in soaked solution was measured using an inductively coupled plasma-atomic emission spectroscopy (ICP-AES). The corrosion surface was characterized by SEM.

\subsection{In Vitro Cell Experiments}

MG-63 cells (American Type Culture Collection, Rockville, USA) were selected to assess the cytocompatibility of Fe/MC composite. Dulbecco's modified Eagle's medium (DMEM) containing 10\% fetal bovine serum, $100 \mathrm{U} / \mathrm{mL}$ penicillin and $100 \mathrm{mg} / \mathrm{mL}$ streptomycin was applied as culture medium. Prior to the experiments, samples were sterilized using ultraviolet light for $30 \mathrm{~min}$, and then immersed in culture medium for $3 \mathrm{~d}$ to obtain the extracts with a solution volume to sample weight ratio of $5 \mathrm{~mL} / \mathrm{g}$. Before the tests, MG-63 cells were cultured in a 96-well plate containing culture medium for $1 \mathrm{~d}$. Then, the culture medium was replaced by extracts. After culture for 1,4 and $7 \mathrm{~d}, 10 \mu \mathrm{L}$ of cell counting kit-8 (CCK-8) reagent was dropped into each well and further incubated for $3 \mathrm{~h}$. Finally, the absorbance was measured using a microplate reader. Moreover, LIVE cells fluorescence staining was used to quantitatively assess the cell viability. After culture for 1, 4, and 7 days, the Calcein-AM reagent were used to stain the cells for $15 \mathrm{~min}$. Then, the stained cells were observed utilizing a fluorescence microscopy (BX60, Olympus, Japan).

\subsection{Statistical Analysis}

Data in the present work were expressed as mean \pm deviations. The one-way ANOVA analysis model was performed to study the statistical significance. When the p-value was below 0.05 , difference was considered to be significant.

\section{Results and Discussion}

\subsection{Microstructure and Phase Composition}

The microstructure of $\mathrm{Fe}$ and $\mathrm{Fe} / \mathrm{MC}$ composites were studied using SEM in secondary electron (SE) and back-scattered (BSE) mode, as presented in Figure 2. The SE model was usually adopted to study the topographic contrast, while the BSE model was favorable to observe the distribution of different phases. It could be seen that the as-built Fe part achieved an extremely high densification rate, without obvious cracks or pores. For Fe/0.5MC and Fe/1.0MC composites, BSE images showed that a small number of black particles were homogeneously located in the matrix. The EDS line-scan results confirmed that these particles belonged to MC. Meanwhile, the SE images also revealed that some pores appeared around the incorporated MC particles, indicating that the incorporation of MC reduced the densification rate of as-built parts. With MC further increasing to $1.5 \mathrm{wt} . \%$, they aggregated into large-scale clusters, as marked by the arrows.

The phase compositions of $\mathrm{Fe}$ and Fe/MC composites were investigated by XRD, with collected spectrum presented in Figure 3. The body-centered cubic $\alpha$-Fe phase (JCPDS No. 06-0696) with (110), (200) and (211) planes was determined in all parts. For Fe/MC composites, an extremely weak peak corresponding to Fe3C phase (JCPDS No. 761877) was determined, whereas no obvious peaks corresponding to $C$ phase were collected. It was speculated that partial $C$ dissolved in $\alpha$-Fe, thus forming the $\mathrm{Fe} 3 \mathrm{C}$ phase [30]. Besides, a close observation revealed that the primary peak in $\alpha$-Fe in Fe/MC composites slightly shifted to a low location, which could be ascribed to the lattice distortion caused by the solid solution of the $\mathrm{C}$ atom [31,32]. 


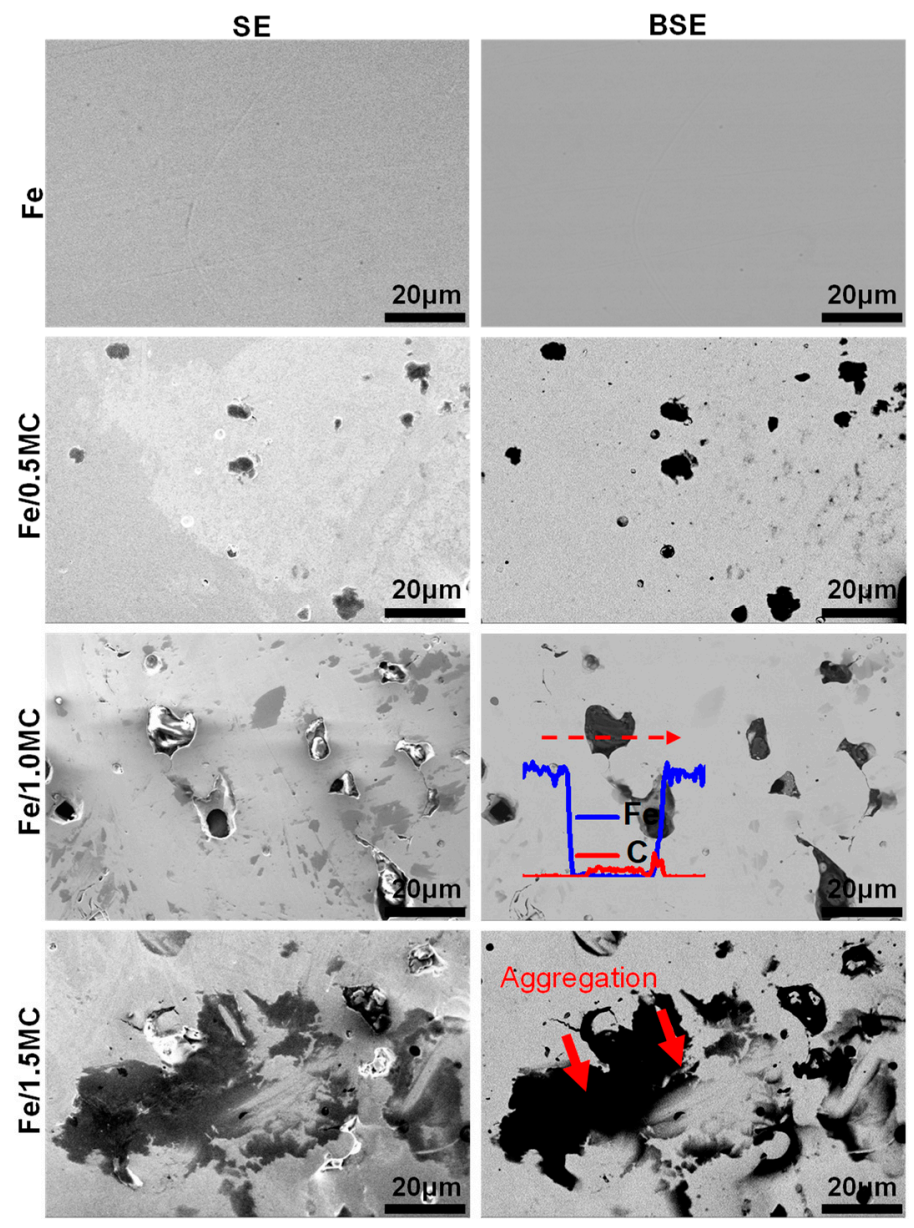

Figure 2. Secondary electron (SE) and back-scattered (BSE) images showed the microstructure of as-built Fe and Fe/MC composites.
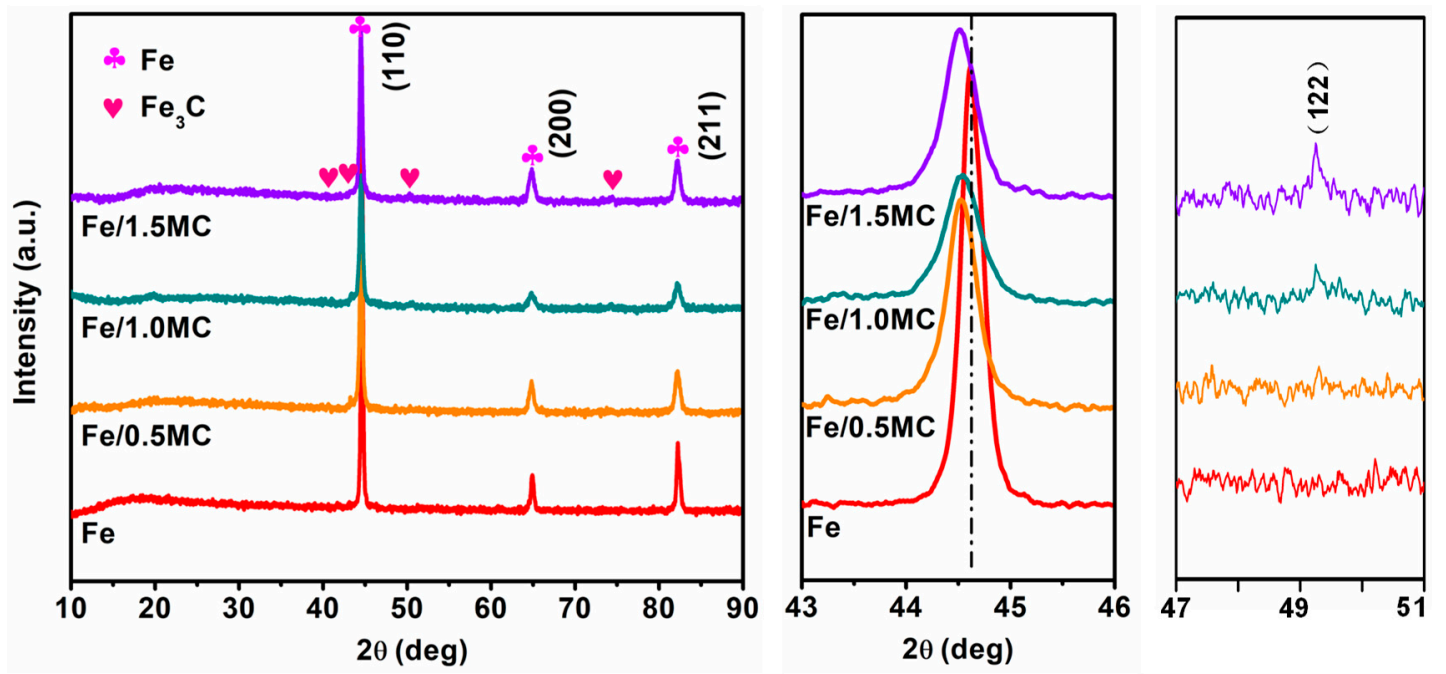

Figure 3. The XRD spectrum of Fe and Fe/MC composites.

\subsection{Mechanical Properties}

The typical tensile stress-strain curves of $\mathrm{Fe}$ and $\mathrm{Fe} / \mathrm{MC}$ composites were presented in Figure 4a. As seen from the curves, the peak stresses of $\mathrm{Fe} / \mathrm{MC}$ composites were obviously larger than that of Fe. The tensile strength and elongation derived from the stress-strain curves were displayed in Figure $4 \mathrm{~b}$. For Fe, the tensile strength was $442.3 \pm 11.1 \mathrm{MPa}$ and elongation was $11.8 \% \pm 0.2 \%$. 
With MC upper reaching $1.0 \mathrm{wt} . \%$, the tensile strength was gradually enhanced to $1032.9 \pm 17.3 \mathrm{MPa}$, while the elongation was reduced to $6.8 \% \pm 0.5 \%$. However, after further increasing MC to $1.5 \mathrm{wt} . \%$, the mechanical properties were decreased slightly, with tensile strength and elongation reducing to $982.4 \pm 22.6$ and $3.6 \% \pm 0.5 \%$, respectively. In fact, micro defects appeared in the matrix of $\mathrm{Fe} / 1.5 \mathrm{MC}$ due to the agglomerates of $\mathrm{MC}$, resulting in a weak interface and poor stress transfer. Thus, the tensile strength was decreased. The fracture surface morphologies of $\mathrm{Fe}$ and Fe/MC composites were presented in Figure 4c-f. It could be seen that Fe presented a typical ductile fracture covered with numerous dimples. With the addition of MC, the number of dimples gradually decreased, which represented a decrease in ductility. The fracture morphologies of Fe/0.5MC and Fe/1.0MC showed a small amount of cleavage planes, indicating a mixed ductile-brittle fracture. Besides, a few MC particles were observed on the tensile fracture surfaces of Fe/1.0MC composites (as marked by red arrows in Figure 4f). As for $\mathrm{Fe} / 1.5 \mathrm{MC}$, the fracture surface was covered by cleavage planes, indicating a typical brittle fracture. It was deduced that a high MC content prevented the large-scale plastic deformation of the matrix, thus reducing the ductility [33].
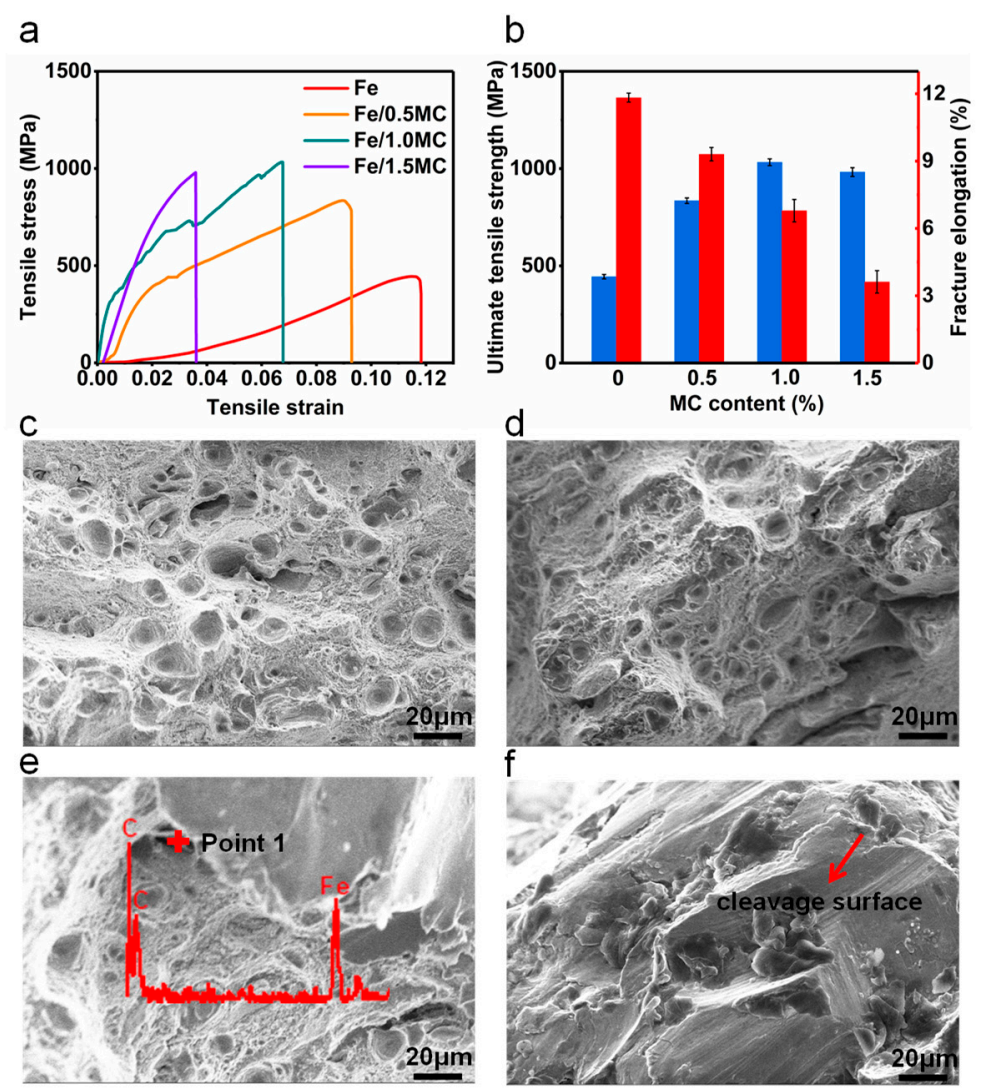

Figure 4. (a) Representative stress-strain curves obtained from tensile tests; (b) The calculated tensile strength and elongation from the stress-strain curves. $\mathrm{n}=3$. Fracture surface morphologies of as-built (4) $\mathrm{Fe},(\mathrm{d}) \mathrm{Fe} / 0.5 \mathrm{MC},(\mathrm{e}) \mathrm{Fe} / 1.0 \mathrm{MC}$ and (f) Fe/1.5MC.

\subsection{Degradation Behavior}

The typical polarization curves of Fe and Fe/MC composites were depicted in Figure 5a. The derived $\mathrm{E}_{\text {corr }}$ and $\mathrm{I}_{\text {corr }}$ using Tafel extrapolation were shown in Figure $5 \mathrm{~b}$. It was obvious that the $\mathrm{E}_{\mathrm{corr}}$ was greatly decreased with $\mathrm{MC}$ increasing. Specifically, the $\mathrm{E}_{\mathrm{corr}}$ was $-0.60 \pm 0.01 \mathrm{~V}$ for $\mathrm{Fe}$, and $-0.67 \pm 0.03$ $\mathrm{V}$ for Fe/1.0MC. Meanwhile, the $\mathrm{I}_{\text {corr }}$ increased from $6.45 \pm 0.36 \mu \mathrm{A} / \mathrm{cm}^{2}$ for Fe to $23.6 \pm 0.9 \mu \mathrm{A} / \mathrm{cm}^{2}$ for Fe/1.5MC. In the Nyquist plots (Figure 5c), the change in the impedance imaginary part (z") was expressed as a function of the impedance real part $\left(z^{\prime}\right)$, which exhibited series semicircles. It was well known that the diameter of the high-frequency capacitive loop represented the polarization 
resistance [34,35]. Obviously, the diameters of semicircles gradually decreased with MC increasing, indicating that their corrosion resistance turned weak. The corrosion rate was also calculated from electrochemical parameters, as shown in Figure $5 \mathrm{~d}$. The Fe/1.0MC composite showed a significantly accelerated corrosion rate of $0.19 \pm 0.02 \mathrm{~mm} /$ year as compared to Fe.

a
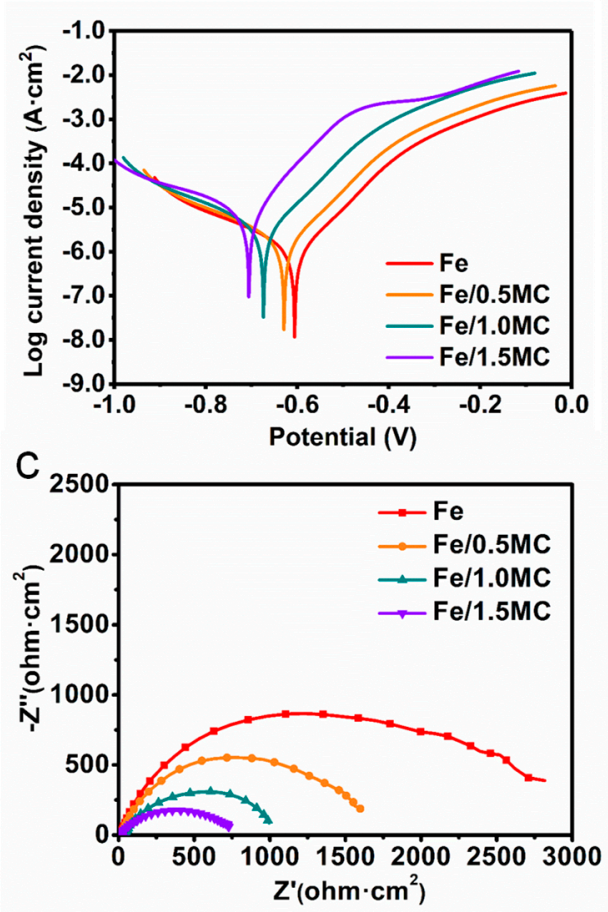

b
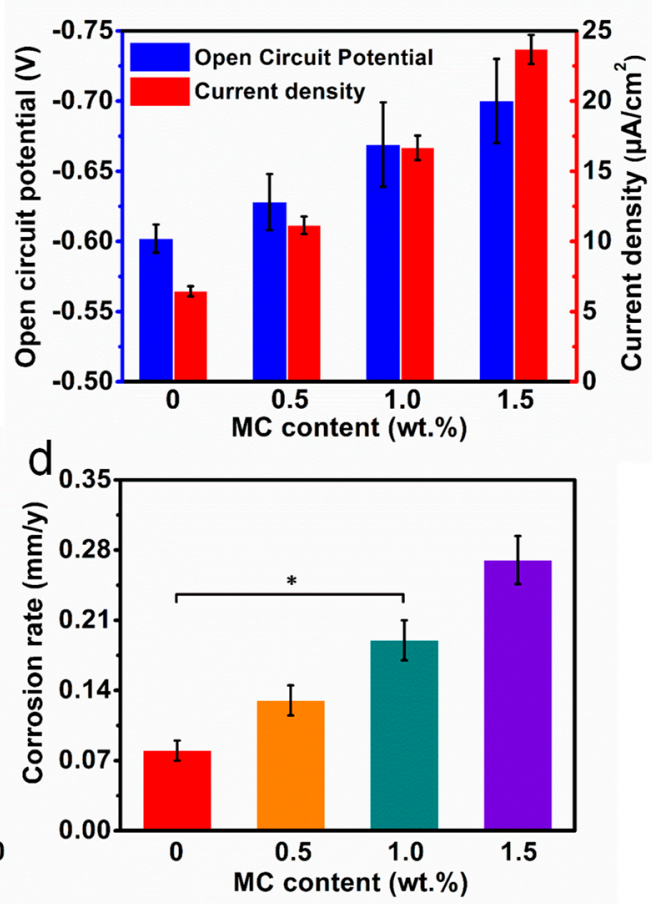

Figure 5. (a) The potential polarization curve; (b) The obtained $\mathrm{E}_{\mathrm{corr}}$ and $\mathrm{I}_{\mathrm{corr}}$ from Tafel extrapolation; (c) The typical Nyquist diagram for the alternating current impedance measurements; (d) Corrosion rates calculated from the electrochemical results. $\mathrm{n}=3,{ }^{*} p<0.05$.

The SEM images of the corroded surface after polarization test were presented in Figure 6. Clearly, Fe exhibited an intact surface with few corrosion products (Figure 6a). For the Fe/0.5MC composite, a few corrosion products appeared. As a comparison, Fe/1.0MC and Fe/1.5MC showed a large amount of corrosion product, which should be Fe oxides, as confirmed by EDS analysis (Figure 6f). This indicated that enhanced corrosion occurred for Fe/1.0MC and Fe/1.5MC. During potentiodynamic polarization, the external driving force was applied to dissolve the Fe matrix. In this condition, the galvanic interactions between the Fe matrix and MC could be ignored. In fact, the introduction of MC created defects in the Fe matrix, as presented in Figure 2, which might be the major reason for the enhancement of electrochemical corrosion. [36,37].

Immersion tests have also been carried out to assess degradation performance from a long-term perspective. The degradation morphologies of Fe and Fe/MC samples after immersion for $21 \mathrm{~d}$ were displayed in Figure 7. Distinctly, a flat corrosion surface with a few local etch pits were observed on Fe, suggesting its slight local corrosion. The corrosion products were composed of Fe and O elements, suggesting that they were Fe oxide and hydroxide. The Fe/0.5MC composite exhibited different corrosion morphology with a small amount of precipitates appearing on the surface (Figure $7 \mathrm{~b}$ ). For the $\mathrm{Fe} / 1.0 \mathrm{MC}$ composite, more corrosion product was observed. EDS analysis exhibited that the corrosion products were mainly composed of $\mathrm{Fe}, \mathrm{O}, \mathrm{Ca}$ and $\mathrm{P}$, demonstrating the deposition of $\mathrm{Ca}-\mathrm{P}$ compounds. For the Fe/1.5MC composite, however, the surface was covered with a heavy corrosion product with some obvious cracks, which demonstrated that the corrosion was significantly aggravated. 


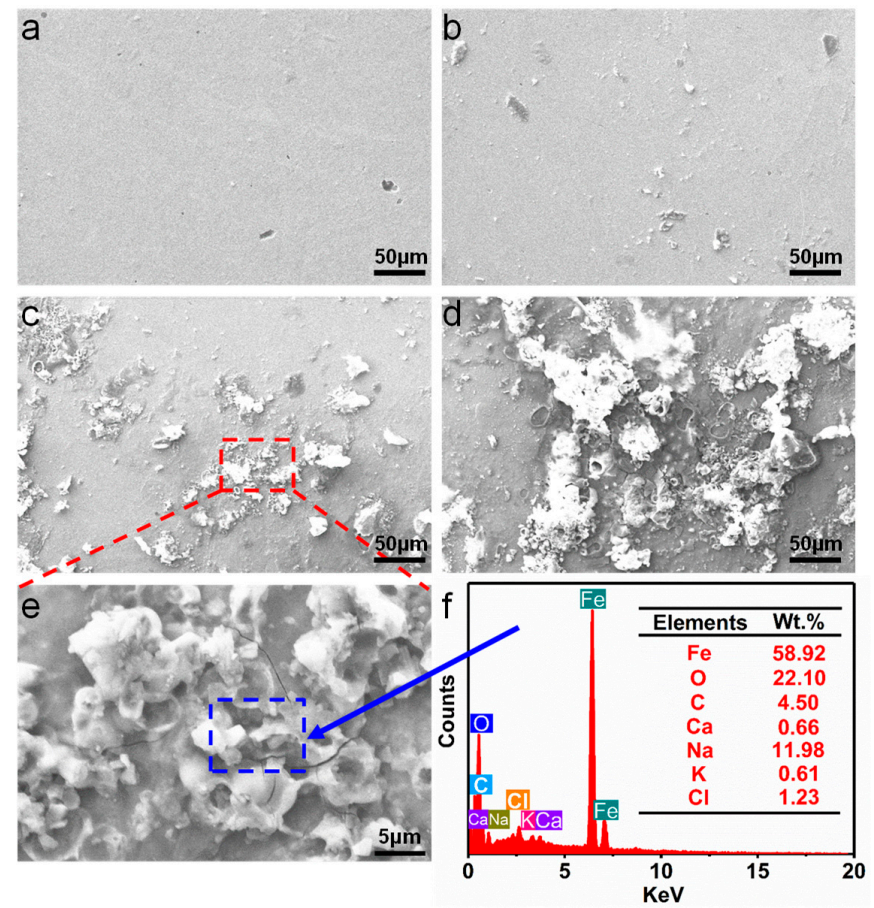

Figure 6. Surface of (a) $\mathrm{Fe},(\mathbf{b}) \mathrm{Fe} / 0.5 \mathrm{MC}$, (c) Fe/1.0MC and (d) Fe/1.5MC after polarization tests; (e) Locally enlarged image of Fe/1.0MC and (f) energy dispersive spectrometer (EDS) analysis of the marked area in Figure 6e.
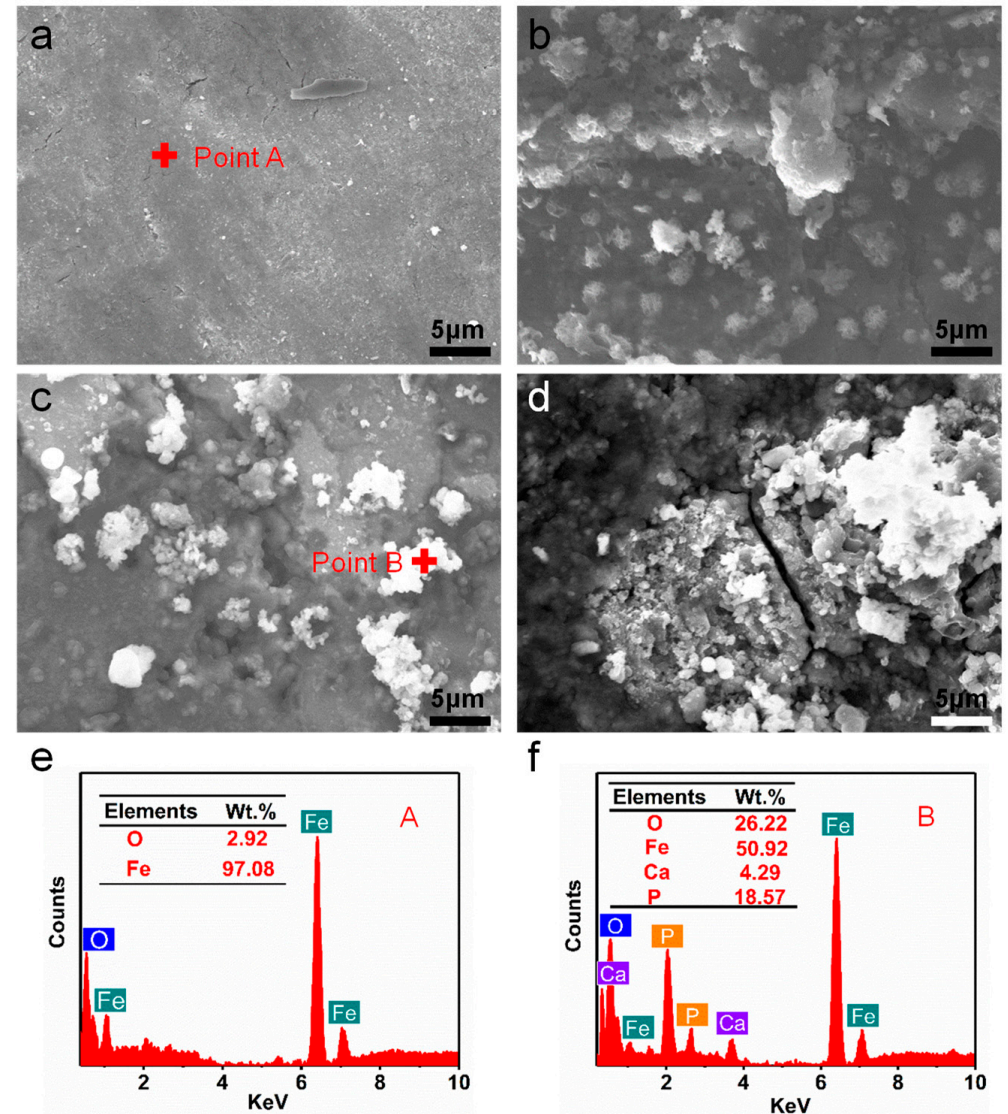

Figure 7. Corrosion surface of (a) Fe, (b) Fe/0.5MC, (c) Fe/1.0MC and (d) Fe/1.5MC composites after immersion for $21 \mathrm{~d}$; (e) and (f) were the corresponding EDS analyses of points A and B, respectively. 
The Fe concentration in SBF at different soaking time was measured by ICP-AES, as presented in Figure 8a. It could be seen that Fe ion concentration increased, with the immersion time extending. For pure Fe, the released Fe ion concentration increased slowly from $3.9 \pm 1.1$ to $7.1 \pm 2.3 \mathrm{mg} / \mathrm{L}$ during four different soaking cycles. After incorporating MC, the released Fe ion concentration increased significantly, indicating an increased degradation rate. In particular, the Fe ion concentration rose rapidly from $7.9 \pm 2.2 \mathrm{mg} / \mathrm{L}$ at day 7 to $14.8 \pm 3.6 \mathrm{mg} / \mathrm{L}$ at day 28 for the $\mathrm{Fe} / 1.0 \mathrm{MC}$ composite. The degradation rate of $\mathrm{Fe} / \mathrm{MC}$ composites basing on immersion tests were shown in Figure 8b. Specifically, Fe exhibited a relatively slow degradation rate of $0.09 \pm 0.01 \mathrm{~mm} /$ year. In contrast, Fe/1.0MC showed a significantly accelerated degradation rate of $0.24 \pm 0.03 \mathrm{~mm} /$ year. A previous research reported that $\mathrm{Zn}$-based bone implants exhibited a corrosion rate of $0.18 \mathrm{~mm} /$ year, while $\mathrm{Mg}$-based bone implants exhibited a corrosion rate of $1.7 \mathrm{~mm} / \mathrm{year}$. In fact, the bone healing period is usually 3-6 months, which requires a degradation rate of $0.2-0.5$ for bone implants. Thus, it seems that the $\mathrm{Fe} / 1.5 \mathrm{MC}$ presented a more suitable degradation rate as bone implants.

a

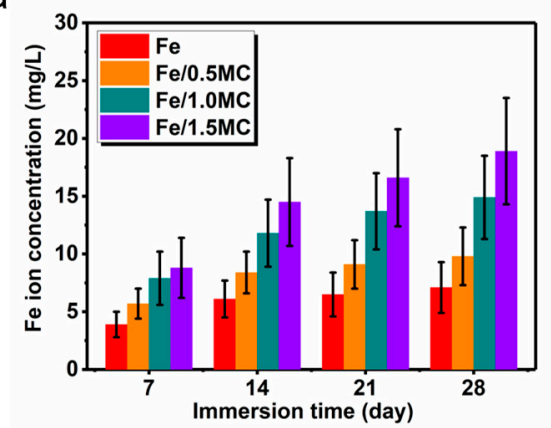

C

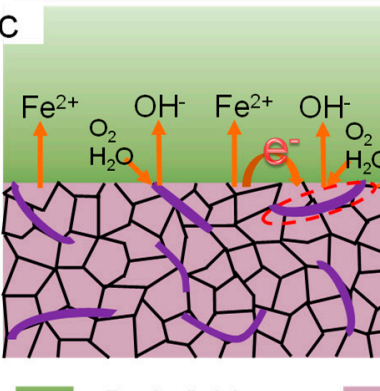

Body fluid

(d)

Fe matrix b
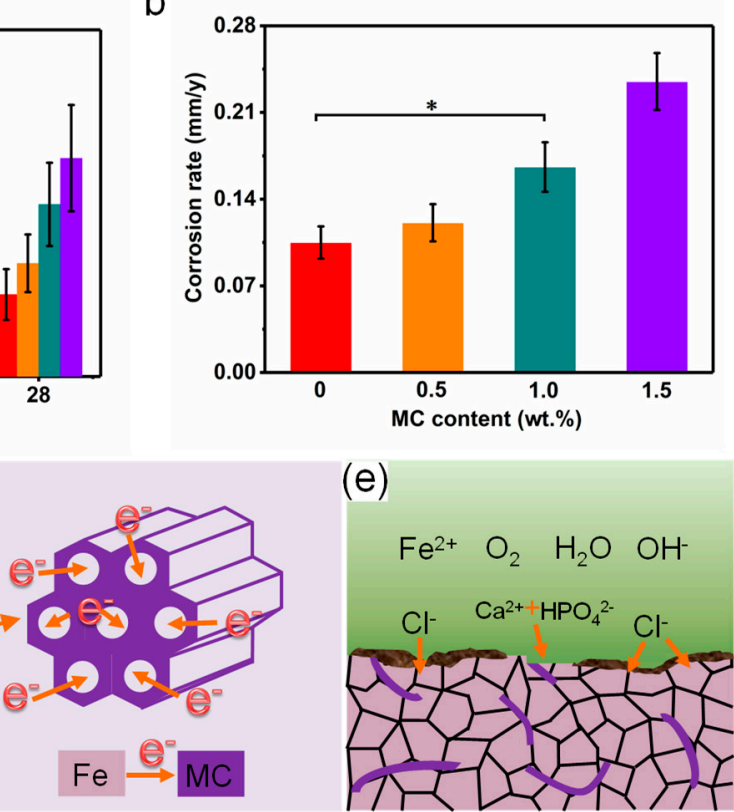

(e)

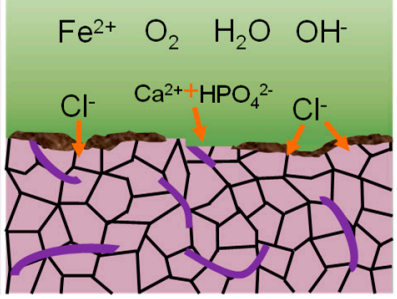

Hydroxide

Figure 8. (a) Fe ion concentrations released from the Fe/MC composites after immersion for 7, 14, 21, and $28 \mathrm{~d}, \mathrm{n}=3{ }^{*} p<0.05$; (b) Calculated degradation rate basing on immersion tests; (c) Initial corrosion stage caused by galvanic corrosion; (d) Local enlarged drawing of electron transfer between galvanic couple; (e) Corrosion products precipitated on surface.

In this work, the electrochemical tests and immersion tests indicated that MC enhanced the degradation rate of Fe. As compared with the electrochemical test, the immersion test with a long period was able to more accurately characterize its degradation behavior [38]. The corrosion mechanism of the Fe/MC composite in body fluid was shown in Figure 8c-e. At the initial corrosion stage, the grain boundaries encountered galvanic corrosion due to the potential difference between grains and grain boundaries [39]. The Fe matrix was gradually dissolved into Fe ions by

$$
\mathrm{Fe} \rightarrow \mathrm{Fe}^{2+}+2 \mathrm{e}^{-}
$$

Electrons raised from the dissolution of Fe matrix moved to MC, where cathodic reaction occurred as follows

$$
2 \mathrm{H}_{2} \mathrm{O}+\mathrm{O}_{2}+4 \mathrm{e}^{-} \rightarrow 4 \mathrm{OH}^{-}
$$


Significantly, MC possessed a mesoporous structure with a large specific surface area, as presented in Figure 8d, which considerably increased the area ratio between the cathode and anode. In this condition, the consumption of anode was accelerated. In addition, MC also exhibited excellent conductivity, which reduced the charge transfer resistance and consequently increased the corrosion current [40]. Due to the enhanced galvanic corrosion, a large amount of corrosion product covered the matrix (Figure 8e), which was generated by the following equation [41]:

$$
\begin{gathered}
\mathrm{Fe}^{2+}+2 \mathrm{OH}^{-} \rightarrow \mathrm{Fe}(\mathrm{OH})_{2} \\
4 \mathrm{Fe}(\mathrm{OH})_{2}+\mathrm{O}_{2}+\mathrm{H}_{2} \mathrm{O} \rightarrow 4 \mathrm{Fe}(\mathrm{OH})_{3} \\
\mathrm{Fe}(\mathrm{OH})_{2}+2 \mathrm{Fe}(\mathrm{OH})_{3} \rightarrow \mathrm{Fe}_{3} \mathrm{O}_{4}+4 \mathrm{H}_{2} \mathrm{O}
\end{gathered}
$$

Nevertheless, the aggressive chloride ion in the physiological environment was able to break through this corrosion product layer, making the corrosion of the iron matrix continue until the whole matrix was disintegrated [42].

\subsection{Cytocompatibility}

Bone implants do not only need a suitable degradation rate, but also good biocompatibility, so as to avoid side effects on the human body after implantation [43-47]. The biocompatibility of $\mathrm{Fe} / 1.0 \mathrm{MC}$ was investigated to evaluate its potential bone repair application. Herein, Fe was used as control. The MG-63 cells exhibited representative polygonal or fusiform shapes after culture for 4 and $7 \mathrm{~d}$, indicating their normal growth [48]. Notably, the cells increased markedly, with culture time increasing from 1 to $7 \mathrm{~d}$. The MG-63 cells began to secrete abundant pseudopods at day 4 , and formed numerous extracellular matrixes with an extended culture time. The cell viability was quantitatively analyzed using CCK-8 assay (Figure 9b). The determined optical densities increased considerably, with culture time increasing, which was consistent with the above fluorescent observation. Meanwhile, no significant difference could be observed between the Fe and Fe/1.0MC after culture for 4 and $7 \mathrm{~d}$. All these results suggested that both $\mathrm{Fe}$ and $\mathrm{Fe} / 1.0 \mathrm{MC}$ were conducive to cell proliferation.
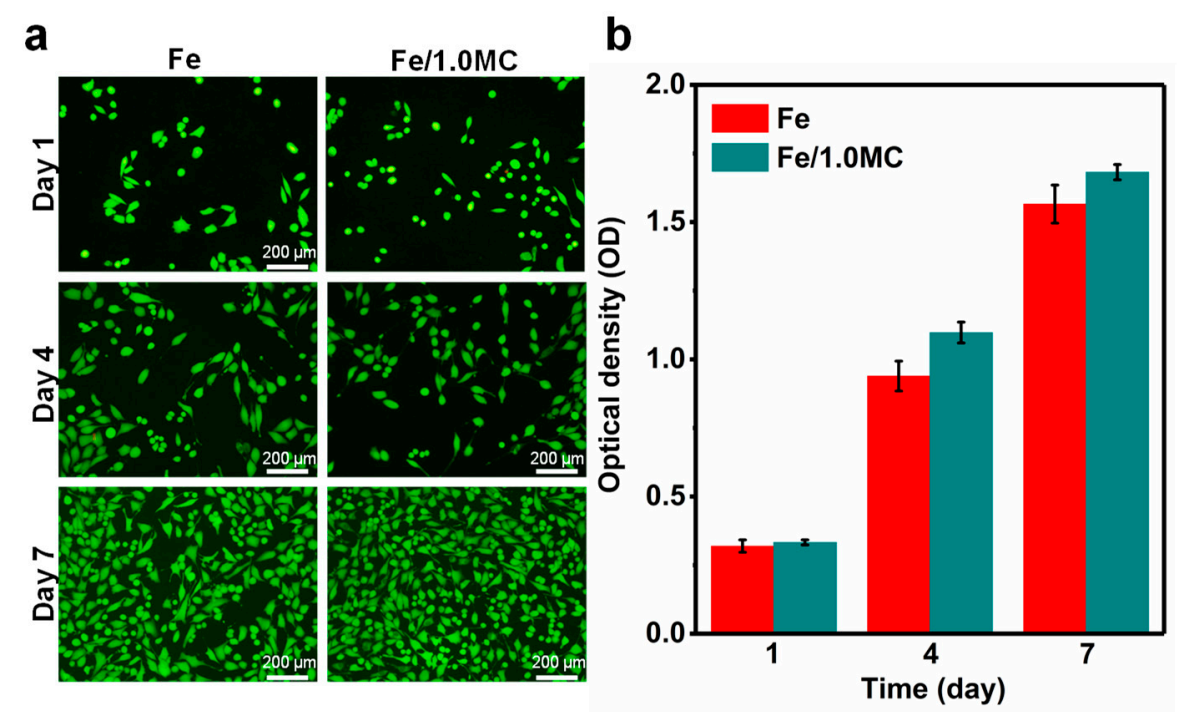

Figure 9. (a) Fluorescent microscopy images of stained cells; (b) CCK-8 assay results of Fe and Fe/1.0MC after 1,4 and $7 \mathrm{~d} . \mathrm{n}=3$.

\section{Conclusions}

In this study, MC was introduced into Fe to improve the degradation behavior. The Fe/MC composite was manufactured by a laser additive manufacturing process. MC with a high specific 
surface area enhanced the area ratio between cathode and anode, thus acting as an effective cathode and activating micro-galvanic corrosion in the Fe matrix. The degradation rates were significantly increased from $0.09 \mathrm{~mm} /$ year for Fe to $0.24 \mathrm{~mm} /$ year for the Fe/1.0MC composite. In addition, the Fe/1.0MC composite showed no obvious cytotoxicity to MG-63 cells. In sum, the Fe/MC composite with high mechanical strength, an enhanced degradation rate and good cytocompatibility was an alternative candidate for bone repair.

Author Contributions: Conceptualization, Y.Y. and C.S.; Validation, S.P.; investigation, Y.L., F.D.; resources, L.S.; writing-review and editing, Y.Y. and C.S.; visualization, F.Q.; project administration, C.S. All authors have read and agreed to the published version of the manuscript.

Funding: This study was supported by the following funds: (1) The Natural Science Foundation of China (51935014, 51905553, 81871494, 81871498, 51705540); (2) Hunan Provincial Natural Science Foundation of China (2019JJ50774, 2018JJ3671, 2019JJ50588); (3) JiangXi Provincial Natural Science Foundation of China (20192ACB20005); (4) Guangdong Province Higher Vocational Colleges \& Schools Pearl River Scholar Funded Scheme (2018); (5) The Open Sharing Fund for the Large-scale Instruments and Equipments of Central South University; (6) The Project of Hunan Provincial Science and Technology Plan (2017RS3008).

Conflicts of Interest: The authors declare no conflict of interest.

\section{References}

1. Yang, C.; Huan, Z.; Wang, X.; Wu, C.; Chang, J. 3D printed Fe scaffolds with HA nanocoating for bone regeneration. Acs Biomater. Sci. Eng. 2018, 4, 608-616. [CrossRef]

2. Tong, X.; Shi, Z.; Xu, L.; Lin, J.; Zhang, D.; Wang, K.; Li, Y.; Wen, C. Degradation behavior, cytotoxicity, hemolysis, and antibacterial properties of electro-deposited $\mathrm{Zn}-\mathrm{Cu}$ metal foams as potential biodegradable bone implants. Acta Biomater. 2019, 102, 481-492. [CrossRef]

3. Shuai, C.; Wang, B.; Bin, S.; Peng, S.; Gao, C. Interfacial strengthening by reduced graphene oxide coated with $\mathrm{MgO}$ in biodegradable Mg composites. Mater. Des. 2020, 191, 108612. [CrossRef]

4. Gao, C.; Yao, M.; Shuai, C.; Peng, S.; Deng, Y. Technology, Nano-SiC reinforced Zn biocomposites prepared via laser melting: Microstructure, mechanical properties and biodegradability. J. Mater. Sci. Technol. 2019, 201935, 2608-2617. [CrossRef]

5. Yang, Y.; He, C.; E, D.; Yang, W.; Qi, F.; Xie, D.; Shen, L.; Peng, S.; Shuai, C. Mg bone implant: Features, developments and perspectives. Mater. Des. 2020, 185, 108259. [CrossRef]

6. Pratesa, Y.; Suharno, B.; Wardhana, A.C.; Harjanto, S. Application of carbamide as foaming agent of FE-MN-C alloy for degradable biomaterial candidate with powder metallurgy process. J. Teknol. 2019, 81. [CrossRef]

7. He, F.; Qian, G.; Ren, W.; Ke, J.; Fan, P.; Shi, X.; Cheng, Y.; Wu, S.; Deng, X.; Ye, J. Preparation and characterization of iron $/ \beta$-tricalcium phosphate bio-cermets for load-bearing bone substitutes. Ceram. Int. 2017, 43, 8348-8355. [CrossRef]

8. Xie, L.; Yang, Y.; Fu, Z.; Li, Y.; Shi, J.; Ma, D.; Liu, S.; Luo, D. Fe/Zn-modified tricalcium phosphate (TCP) biomaterials: Preparation and biological properties. Rsc Adv. 2019, 9, 781-789. [CrossRef]

9. Wang, H.; Zheng, Y.; Jiang, C.; Li, Y.; Fu, Y. In vitro corrosion behavior and cytocompatibility of pure Fe implanted with Ta. Surface and Coatings Technology 2017, 320, 201-205. [CrossRef]

10. Wang, H.; Zheng, Y.; Liu, J.; Jiang, C.; Li, Y. In vitro corrosion properties and cytocompatibility of Fe-Ga alloys as potential biodegradable metallic materials. Mater. Sci. Eng. C 2017, 71, 60-66. [CrossRef]

11. Sikora-Jasinska, M.; Chevallier, P.; Turgeon, S.; Paternoster, C.; Mostaed, E.; Vedani, M.; Mantovani, D. Long-term in vitro degradation behaviour of $\mathrm{Fe}$ and $\mathrm{Fe} / \mathrm{Mg} 2 \mathrm{Si}$ composites for biodegradable implant applications. Rsc Adv. 2018, 8, 9627-9639. [CrossRef]

12. Li, H.; Wang, Y.; Peng, Q. High degradation rate of Fe-20Mn-based bio-alloys by accumulative cryo-rolling and annealing. Mater. Sci. Eng. C. 2017, 79, 37-44. [CrossRef] [PubMed]

13. Huang, T.; Cheng, J.; Zheng, Y. In vitro degradation and biocompatibility of Fe-Pd and Fe-Pt composites fabricated by spark plasma sintering. Mater. Sci. Eng. C 2014, 35, 43-53. [CrossRef] [PubMed]

14. Sharipova, A.; Swain, S.; Gotman, I.; Starosvetsky, D.; Psakhie, S.; Unger, R.; Gutmanas, E. Mechanical, degradation and drug-release behavior of nano-grained Fe-Ag composites for biomedical applications. J. Mech. Behav. Biomed. Mater. 2018, 86, 240-249. [CrossRef] 
15. Shuai, C.; Yang, W.; Yang, Y.; Pan, H.; He, C.; Qi, F.; Xie, D.; Liang, H. Selective laser melted Fe-Mn bone scaffold: Microstructure, corrosion behavior and cell response. Mater. Res. Express 2020, 7, 015404. [CrossRef]

16. Čapek, J.; Msallamová, Š.; Jablonská, E.; Lipov, J.; Vojtěch, D. A novel high-strength and highly corrosive biodegradable Fe-Pd alloy: Structural, mechanical and in vitro corrosion and cytotoxicity study. Mater. Sci. Eng. C 2017, 79, 550-562. [CrossRef]

17. Zhao, Y.-C.; Tang, Y.; Zhao, M.-C.; Liu, C.; Liu, L.; Gao, C.-D.; Shuai, C.; Atrens, A. Study on Fe-xGO Composites Prepared by Selective Laser Melting: Microstructure, Hardness, Biodegradation and Cytocompatibility. JOM 2019, 72, 1163-1174. [CrossRef]

18. Atkins, P.; Overton, T. Shriver and Atkins' Inorganic Chemistry; Oxford University Press: Oxford, UK, 2010.

19. Ma, T.-Y.; Liu, L.; Yuan, Z.-Y. Direct synthesis of ordered mesoporous carbons. Chem. Soc. Rev. 2013, 42, 3977-4003. [CrossRef]

20. Shuai, C.; Li, S.; Wang, G.; Yang, Y.; Peng, S.; Gao, C. Strong corrosion induced by carbon nanotubes to accelerate Fe biodegradation. Mater. Sci. Eng. C 2019, 104, 109935. [CrossRef]

21. Wang, Z.; Wang, Y.; Wang, C. Area Ratio of Cathode/Anode Effect on the Galvanic Corrosion of High Potential Difference Coupling in Seawater; IOP Conference Series: Materials Science and Engineering; IOP Publishing: Bristol, UK, 2018; p. 022046.

22. Hu, S.; Liu, R.; Liu, L.; Cui, Y.; Oguzie, E.E.; Wang, F. Effect of hydrostatic pressure on the galvanic corrosion of 90/10 Cu-Ni alloy coupled to Ti6Al4V alloy. Corros. Sci. 2019, 163, 108242. [CrossRef]

23. Li, Z.; Zhang, J.; Guan, B.Y.; Lou, X.W. Mesoporous Carbon@ Titanium Nitride Hollow Spheres as an Efficient SeS2 Host for Advanced Li-SeS2 Batteries. Angew. Chem. Int. Ed. 2017, 56, 16003-16007. [CrossRef] [PubMed]

24. Wang, J.; Xu, Y.; Ding, B.; Chang, Z.; Zhang, X.; Yamauchi, Y.; Wu, K.C.W. Confined Self-Assembly in Two-Dimensional Interlayer Space: Monolayered Mesoporous Carbon Nanosheets with In-Plane Orderly Arranged Mesopores and a Highly Graphitized Framework. Angewandte Chemie International Edition 2018, 57, 2894-2898. [CrossRef] [PubMed]

25. Vallet-Regí, M. Ordered mesoporous materials in the context of drug delivery systems and bone tissue engineering. Chem.-A Eur. J. 2006, 12, 5934-5943.

26. Shuai, C.; Yuan, X.; Yang, W.; Peng, S.; He, C.; Feng, P.; Qi, F.; Wang, G. Cellulose nanocrystals as biobased nucleation agents in poly-l-lactide scaffold: Crystallization behavior and mechanical properties. Polym. Test. 2020, 85, 106458. [CrossRef]

27. Shuai, C.; Cheng, Y.; Yang, W.; Feng, P.; Yang, Y.; He, C.; Qi, F.; Peng, S. Magnetically actuated bone scaffold: Microstructure, cell response and osteogenesis. Compos. Part B Eng. 2020, 192, 107986. [CrossRef]

28. Shuai, C.; Zeng, Z.; Yang, Y.; Qi, F.; Peng, S.; Yang, W.; He, C.; Wang, G.; Qian, G. Graphene oxide assists polyvinylidene fluoride scaffold to reconstruct electrical microenvironment of bone tissue. Mater. Des. 2020, 190, 108564. [CrossRef]

29. Yang, Y.; Zan, J.; Yang, W.; Qi, F.; he, C.; Huang, S.; Peng, S.; Shuai, C. Metal organic framework as compatible reinforcement in biopolymer bone scaffold. Mater. Chem. Front. 2020, 4, 973-984. [CrossRef]

30. Cheng, J.; Zheng, Y. In vitro study on newly designed biodegradable Fe-X composites (X= W, CNT) prepared by spark plasma sintering. J. Biomed. Mater. Res. Part B: Appl. Biomater. 2013, 101, 485-497. [CrossRef]

31. Wang, C.; Zhang, S.; Shen, Q.; Zhang, L. Investigation on reactive sintering process of boron carbide ceramics by XRD. Mater. Sci. Technol. 2009, 25, 809-812. [CrossRef]

32. Yuan, Q.; Xu, G.; Liu, S.; Liu, M.; Hu, H.; Li, G. Effect of rolling reduction on microstructure and property of ultrafine grained low-carbon steel processed by cryorolling martensite. Metals 2018, 8, 518. [CrossRef]

33. Abdizadeh, H.; Baghchesara, M. Investigation into the mechanical properties and fracture behavior of A356 aluminum alloy-based $\mathrm{ZrO}$ 2-particle-reinforced metal-matrix composites. Mech. Compos. Mater. 2013, 49, 571-576. [CrossRef]

34. Lai, D.; Kong, G.; Che, C. Synthesis and corrosion behavior of $\mathrm{ZnO} / \mathrm{SiO} 2$ nanorod-sub microtube superhydrophobic coating on zinc substrate. Surf. Coat. Technol. 2017, 315, 509-518. [CrossRef]

35. Solmaz, R. Gold-supported activated NiZn coatings: Hydrogen evolution and corrosion studies. Int. J. Energy Res. 2017, 41, 1452-1459. [CrossRef]

36. Meng, J.; Sun, W.; Tian, Z.; Qiu, X.; Zhang, D. Corrosion performance of magnesium (Mg) alloys containing rare-earth (RE) elements. In Corrosion Prevention of Magnesium Alloys; Elsevier: Amsterdam, The Netherlands, 2013; pp. 38-60. 
37. Zhou, Y.; Du, C.; Han, G.; Gao, Y.; Yin, G. Ultra-low Pt decorated PdFe alloy nanoparticles for formic acid electro-oxidation. Electrochimica Acta 2016, 217, 203-209. [CrossRef]

38. Shuai, C.; Zan, J.; Yang, Y.; Peng, S.; Yang, W.; Qi, F.; Shen, L.; Tian, Z. Surface modification enhances interfacial bonding in PLLA/MgO bone scaffold. Mater. Sci. Eng. C 2020, 108, 110486. [CrossRef]

39. Prabhu, T.R. An overview of high-performance aircraft structural Al alloy-AA7085. Acta Metall. Sin. (Engl. Lett.) 2015, 28, 909-921. [CrossRef]

40. Sun, W.; Wang, L.; Wu, T.; Dong, C.; Liu, G. Tuning the functionalization degree of graphene: Determining critical conditions for inhibiting the corrosion promotion activity of graphene/epoxy nanocomposite coatings. Mater. Lett. 2019, 240, 262-266. [CrossRef]

41. Cheng, J.; Huang, T.; Zheng, Y. Microstructure, mechanical property, biodegradation behavior, and biocompatibility of biodegradable Fe-Fe2O3 composites. J. Biomed. Mater. Res. Part A 2014, 102, 2277-2287. [CrossRef]

42. Liu, B.; Zheng, Y. Effects of alloying elements (Mn, Co, Al, W, Sn, B, C and S) on biodegradability and in vitro biocompatibility of pure iron. Acta Biomater. 2011, 7, 1407-1420. [CrossRef]

43. Feng, P.; Kong, Y.; Yu, L.; Li, Y.; Gao, C.; Peng, S.; Pan, H.; Zhao, Z.; Shuai, C. Molybdenum disulfide nanosheets embedded with nanodiamond particles: Co-dispersion nanostructures as reinforcements for polymer scaffolds. Appl. Mater. Today 2019, 17, 216-226. [CrossRef]

44. Feng, P.; Jia, J.; Peng, S.; Yang, W.; Bin, S.; Shuai, C. Graphene oxide-driven interfacial coupling in laser 3D printed PEEK/PVA scaffolds for bone regeneration. Virtual Phys. Prototyp. 2020. [CrossRef]

45. Qian, G.; Lu, T.; Zhang, J.; Liu, R.; Wang, Z.; Yu, B.; Li, H.; Shi, H.; Ye, J. Promoting bone regeneration of calcium phosphate cement by addition of PLGAmicrospheres and zinc silicate via synergistic effect of in-situ pore generation, bioactive ion stimulation and macrophage immunomodulation. Appl. Mater. Today 2020, 19, 100615. [CrossRef]

46. Wang, G.; He, C.; Yang, W.; Qi, F.; Qian, G.; Peng, S.; Shuai, C. Surface-Modified Graphene Oxide with Compatible Interface Enhances Poly-L-Lactic Acid Bone Scaffold. J. Nanomater. 2020, 2020, 5634096. [CrossRef]

47. Shuai, C.; Liu, G.; Yang, Y.; Yang, W.; He, C.; Wang, G.; Liu, Z.; Qi, F.; Peng, S. Functionalized BaTiO3 enhances piezoelectric effect towards cell response of bone scaffold. Colloids Surf. B Biointerfaces 2020, 185, 110587. [CrossRef] [PubMed]

48. He, S.; Yang, S.; Zhang, Y.; Li, X.; Gao, D.; Zhong, Y.; Cao, L.; Ma, H.; Liu, Y.; Li, G.; et al. LncRNA ODIR1 Inhibits Osteogenic Differentiation of hUC-MSCs through the FBXO25/H2BK120ub/H3K4me3/OSX Axis. Cell Death Dis. 2019, 10,1-16. [CrossRef] [PubMed] 